\title{
Nonvital Bleaching: A Case Series on whitening Procedure for Discolored Endodontically Treated Teeth
}

\author{
${ }^{1}$ Shilpi Awadhiya, ${ }^{2}$ Anu Narang, ${ }^{3}$ Manish Agarwal, ${ }^{4}$ Mahendra Jain
}

\begin{abstract}
Discoloration of tooth can be extrinsic or intrinsic based on its etiology, site, appearance, and severity. It poses esthetic problem which could be a prime concern for many patients, especially in anterior region of teeth that may be compromised due to previous trauma, caries, or failed restorations. Bleaching is a more conservative approach which is noninvasive as compared with other prosthodontic options like crowns or veneers. Among various bleaching techniques, "Walking bleach technique" is preferred, as it provides better cosmetic outcome with limited side effects. However, some modifications of it were also introduced. This article aims at presenting a case series on walking bleach method performed on endodontically treated teeth showing good prognosis and superior esthetic results (with no reversal of tooth discoloration).
\end{abstract}

Keywords: Carbamide peroxide, Discoloration, Intracoronal bleaching, Nonvital tooth, Tooth bleaching, Walking bleach method.

How to cite this article: Awadhiya S, Narang A, Agarwal M, Jain M. Nonvital Bleaching: A Case Series on whitening Procedure for Discolored Endodontically Treated Teeth. Int J Prosthodont Restor Dent 2018;8(1):28-31.

Source of support: Nil

Conflict of interest: None

\section{INTRODUCTION}

With the growing concern toward cosmetics, especially in young adults, increased cases of tooth-whitening procedure have been noted in dental practice over the last decade with more preference to minimal invasive technique.

Among various reasons of tooth discoloration, the main etiological factor has to be diagnosed that is directly related to the type of treatment plan and its outcome.

Traditionally, full veneer crowns are preferred for restoring esthetics in anterior endodontically treated teeth, but in cases with sound tooth structure and

\footnotetext{
${ }^{1,4}$ Postgraduate Student, ${ }^{2}$ Associate Professor, ${ }^{3}$ Professor and Head

${ }^{1-4}$ Department of Conservative Dentistry and Endodontics People's College of Dental Sciences and Research Centre Bhopal, Madhya Pradesh, India

Corresponding Author: Shilpi Awadhiya, Postgraduate Student Department of Conservative Dentistry and Endodontics, People's College of Dental Sciences and Research Centre, Bhopal Madhya Pradesh, India, Phone: +919669975999, e-mail: shilpi. soni.22@gmail.com
}

mild-to-moderate discoloration, bleaching is a better option, as it is noninvasive, less time-consuming, and economical. ${ }^{1-4}$

Walking bleach method is a preferable method for intracoronal discoloration which uses sodium perborate mixed with $3 \%$ hydrogen peroxide or mixed with distilled water.

This mixture releases $\mathrm{H}_{2} \mathrm{O}_{2}$ that in turn reacts with pulp disintegration products that cause discoloration inside the tooth. The outcome of the bleaching depends mainly on the concentration of the bleaching agent, ability of the agent to reach the chromogenic molecules, and duration as well as frequency of application of agent. ${ }^{4}$

Intrinsic discoloration may be caused by systemic or local factors, and systemic reasons include drug-related (tetracycline) metabolic fluorosis, and genetic (hyperbilirubinemia, amelogenesis imperfecta, and dentinogenesis imperfecta). ${ }^{5}$

Local reasons may be because of necrosis of pulp, intrapulpal hemorrhage, pulp tissue remnants after endodontic therapy, endodontic materials, coronal filling materials, root resorption, and aging. ${ }^{6}$

This article aims at presenting a case series that shows successful bleaching of discolored nonvital endodontically treated teeth with walking bleach technique performed with two different approaches associated with good prognosis and no side effects.

\section{CASE REPORTS}

\section{Case 1}

A 25-year-old female patient reported to the Department of Conservative Dentistry and Endodontics of the people's hospital with complaint of discolored upper left anterior teeth. Patient had a history of trauma with anterior teeth 5 years back and she had undergone root canal treatment for the same. Intraoral examination revealed brownish discolored maxillary left central incisor (Fig. 1). An intraoral radiograph showed obturation and normal periapical tissue with 21 , and the patient was explained about the treatment of bleaching for the tooth and informed consent was taken. To determine the shade of teeth preoperatively, Vita classic porcelain shade guide (Vita zahafabi) was used under normal daylight and preoperative photographs were taken (Fig. 2). The pulp chamber was prepared prior to application of bleaching agent by removing $2 \mathrm{~mm}$ 


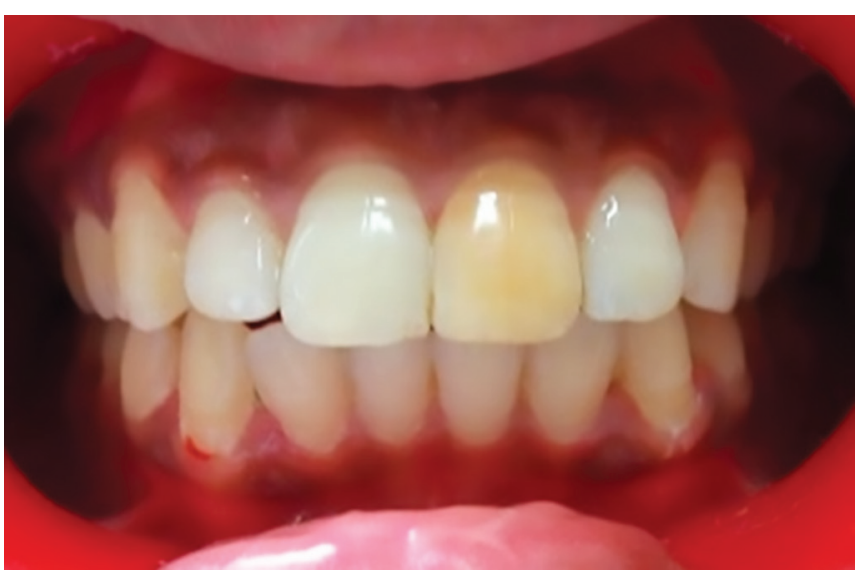

Fig. 1: Pretreatment view

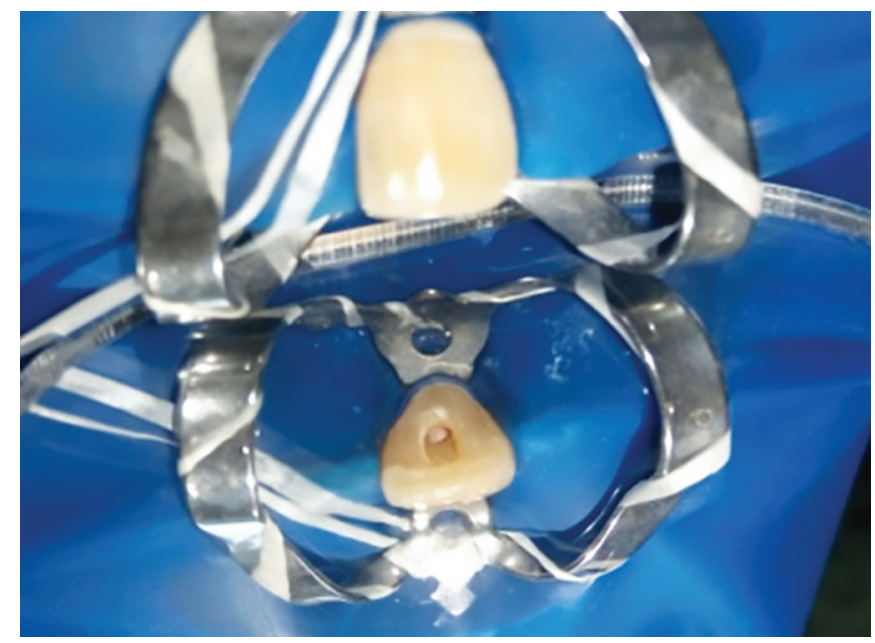

Fig. 3: Mechanical barrier formed with glass ionomer cement before application of bleaching agent

of gutta-percha near orifice and placing a base of 1 to $2 \mathrm{~mm}$ glass ionomer cement (GIC) over the gutta-percha to create a mechanical barrier between the sealed root canal and bleaching agent to be used in pulp chamber (Fig. 3). Nonvital bleaching with a mixture of sodium perborate and $3 \%$ hydrogen peroxide [sodium perborate and $3 \% \mathrm{H}_{2} \mathrm{O}_{2}$ in ratio of 2:1 $\left.(\mathrm{gm} / \mathrm{mL})\right]$ was decided for this patient and bleaching procedure was performed. After placement, the cavity was sealed with temporary restorative material and the patient was recalled every week for repeating the bleaching procedure so as to obtain the desired results. Before proceeding ahead, in each visit, the result was clinically evaluated comparing the teeth shade with the previous one using Vita shade guide and photographs taken earlier.

After a few visits, the shade of the teeth gets lightened to a superior esthetic shade with accepted clinical success; thereafter, the teeth were permanently restored using composite resin.

The tooth showed significant changes in shade after 3 days (Fig. 4) and after 2 weeks (Fig. 5).

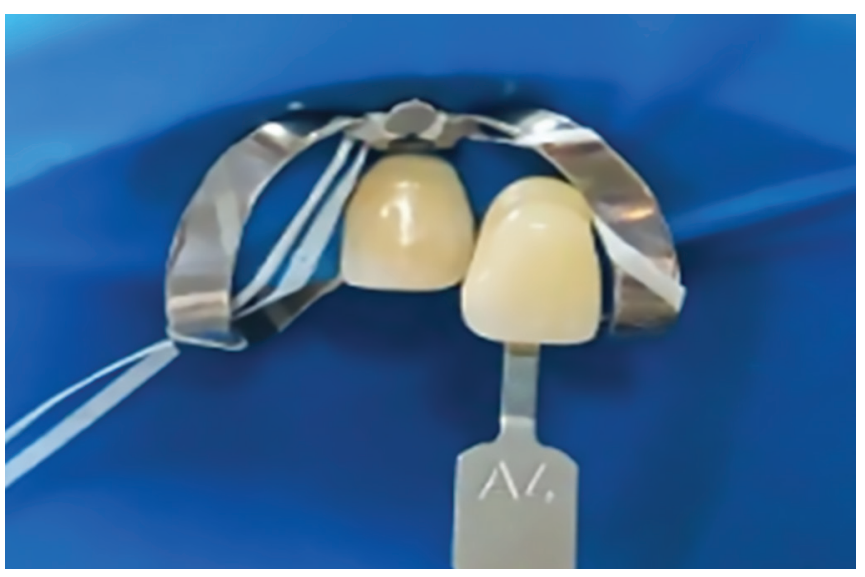

Fig. 2: Preoperative shade of the discolored tooth

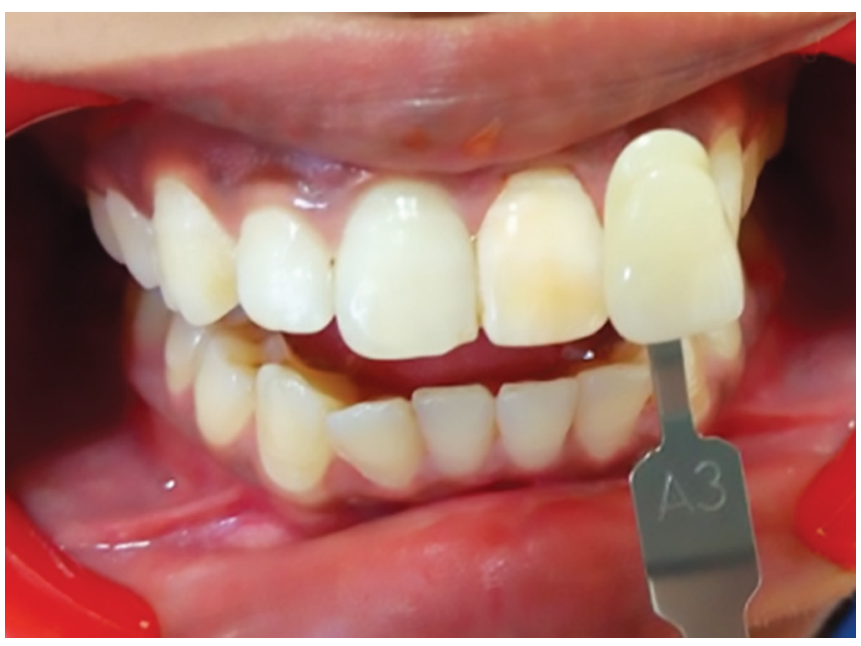

Fig. 4: Change in color after 3 days

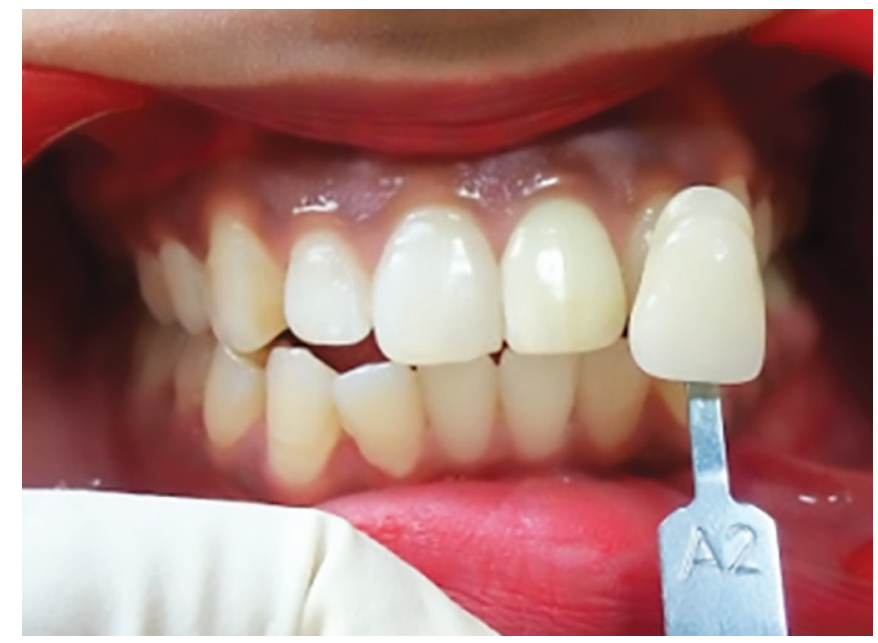

Fig. 5: Change in color after 2 weeks

\section{Case 2}

A 16-year-old girl reported to the Department of Conservative Dentistry and Endodontics with a history of discolored teeth in upper right front teeth region that previously had suffered trauma during childhood about 10 years 

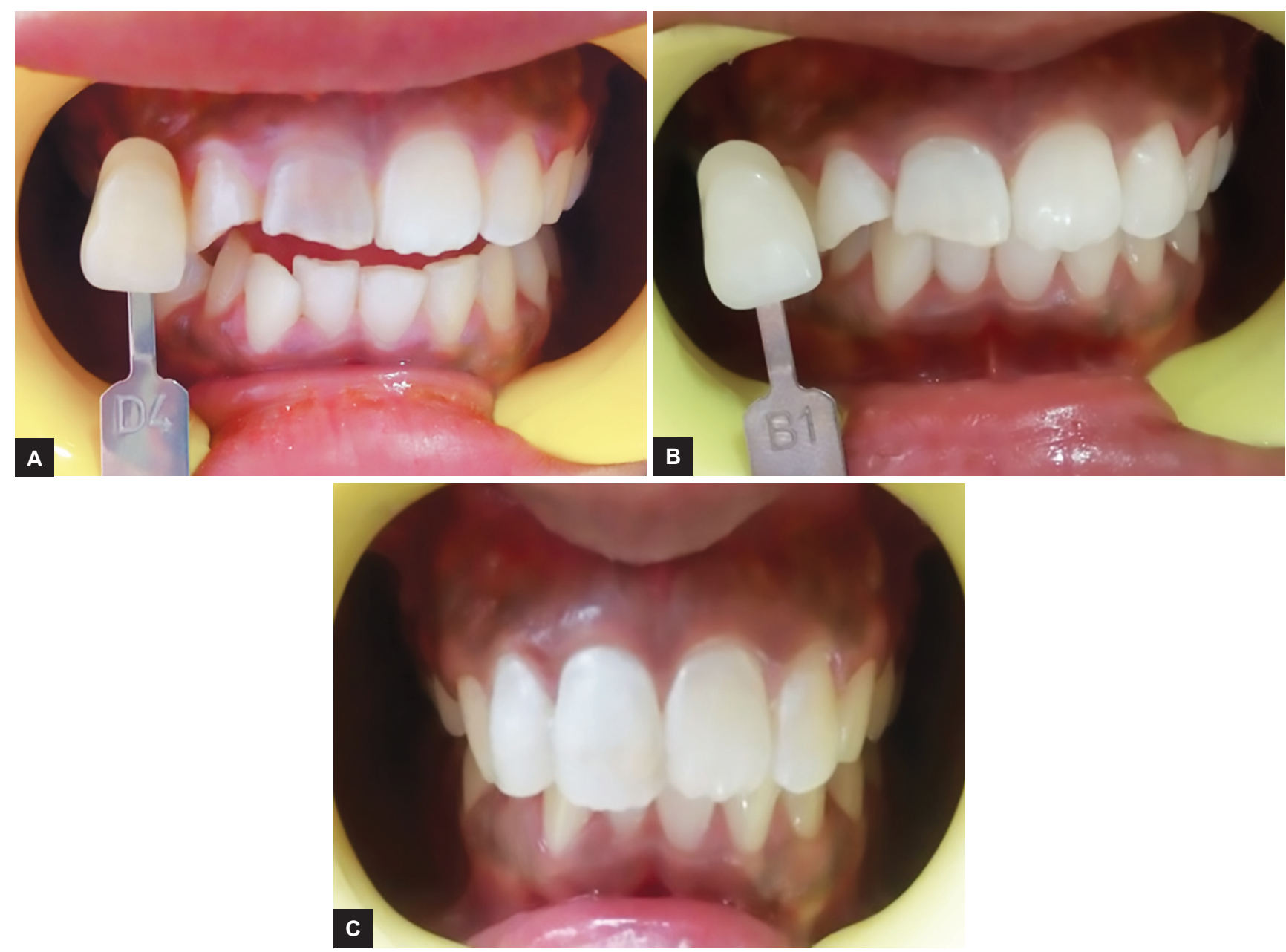

Figs 6A to C: (A) Discolored central and lateral incisors; (B) results after bleaching; and (C) result after esthetic buildup

back. Electric pulp test showed results of both teeth being nonvital; diagnosis and treatment plan was explained to the patient and consent was taken for treatment.

To determine the shade of teeth preoperatively, Vita classic porcelain shade guide (Vita zahafabi) was used under normal daylight, and preoperative photographs as shown in Figure 6A were taken. Thereafter, conventional endodontic treatment was carried out. The pulp chamber was prepared for bleaching by removing $2 \mathrm{~mm}$ of gutta-percha near orifice and 1 to $2 \mathrm{~mm}$ GIC was placed over it to create a mechanical barrier between the sealed root canal and bleaching agent to be used in pulp chamber.

Bleaching was carried out using a paste of sodium perborate prepared by mixing with $10 \%$ carbamide peroxide. The patient was recalled every week for repeating the procedure so as to obtain desired results.

After a few visits, the desired results were obtained with better cosmetic appearance as the shade got lighter (Fig. 6B). Thereafter, permanent restoration was given to both the teeth and esthetic build-up was done with composite (Fig. 6C).

\section{DISCUSSION}

Bleaching of discolored nonvital teeth was first reported during the mid-19th century for which the bleaching agent of choice was chloride of lime, ${ }^{7}$ and other agents described for bleaching of pulpless teeth included aluminum chloride, oxalic acid initially, until tooth bleaching effect of $\mathrm{H}_{2} \mathrm{O}_{2}$ was discovered in 1884 to be used for bleaching. ${ }^{8}$

Some chemicals like cyanide of potassium were also used but they were poisonous in nature; if not used with precaution, it produces ill effects. A 3\% solution of pyrozone was used safely as a mouthwash as early as 1890, which reduced caries and also considered lightened discolored tooth. ${ }^{9}$

Sodium perborate was also introduced in bleaching application. It is an oxidizing agent containing 95\% perborate which occurs in the form of mono, tri $\left(\mathrm{NaBO}_{2}\right.$. $\mathrm{H}_{2} \mathrm{O}_{2} \cdot 3 \mathrm{H}_{2} \mathrm{O}$ ) or tetrahydrate. ${ }^{10}$ Walking bleach method was first explained by Spasser ${ }^{11}$ which utilizes sodium perborate mixed with distilled water. Sodium perborate when mixed with water releases $\mathrm{H}_{2} \mathrm{O}_{2}$. This method was 
later modified by Nutting and $\mathrm{Poe}^{12}$ replacing $\mathrm{H}_{2} \mathrm{O}$ with $30 \% \mathrm{H}_{2} \mathrm{O}_{2}$ to improve the effect, but it increased the risk of external cervical root resorption, and hence, is to be used with caution. The pigmentation that causes intrinsic discoloration from necrotic pulp consists of long chain of organic molecule. Bleaching using $\mathrm{H}_{2} \mathrm{O}_{2}$ oxidizes these long-chain molecules and transform them into carbon while releasing $\mathrm{H}_{2} \mathrm{O}$ and oxygen. ${ }^{13}$

An improvement was found in vitro when sodium perborate was mixed with carbamide peroxide instead of distilled water in a concentration of 10 to $35 \%{ }^{14}$

Carbamide peroxide $\left(\mathrm{CH}_{4} \mathrm{~N}_{2} \mathrm{O} \cdot \mathrm{H}_{2} \mathrm{O}_{2}\right)$ is an organic compound containing $\mathrm{H}_{2} \mathrm{O}_{2}$ and urea products which contain $10 \%$ carbamide peroxide and release $3.5 \%$ hydrogen. ${ }^{15}$

Internal bleaching requires healthy periodontal tissues and a root canal that is properly treated to prevent the bleaching agent from leaking into the periapical tissue. Most in vitro studies have concluded that sodium perborate in water, sodium perborate in $3 \% \mathrm{H}_{2} \mathrm{O}_{2}$ or $30 \%$ $\mathrm{H}_{2} \mathrm{O}_{2}$ and $10 \%$ carbamide peroxide are efficient agents for internal bleaching of nonvital teeth. ${ }^{16}$

Bleaching methods include thermocatalytic, walking bleach, or combination of these. In thermocatalytic technique, a heat source is used to activate bleaching agent placed in pulp through release of nascent oxygen (it is not advisable to use thermocatalytic method with 30\% $\mathrm{H}_{2} \mathrm{O}_{2}$, as it may cause leakage of bleaching agent into dentinal tubules with initiated inflammation during treatment). ${ }^{16}$

Walking bleach method involves application of a thick paste of sodium perborate mixed with $\mathrm{H}_{2} \mathrm{O}_{2}$ or water into pulp chamber for a period of 3 to 7 days followed by recall visits for review and repeat of procedure till desired results are achieved. When the bleaching agent is applied inside the pulp chamber and sealed, the bleaching occurs between dental appointments through this walking bleach technique.

Other modifications in this technique can be using higher concentration of $\mathrm{H}_{2} \mathrm{O}_{2}$ or $10 \%$ carbamide peroxide with sodium perborate or additionally adding thermocatalytic action with this, but it poses the risk of external cervical resorption which could become a serious complication. According to Howell, the walking bleach technique has an immediate success rate of $89.5 \%$.

\section{CONCLUSION}

This article aims at highlighting the efficiency of the nonvital bleaching method using sodium perborate with $3 \%$ hydrogen peroxide and alternatively with $10 \%$ carbamide peroxide to attain successful and predictable cosmetic results. Both the cases were followed up for
2 months with no signs of reversal of discoloration or root resorption. Therefore, it can be concluded that walking bleach method can be the treatment of choice for nonvital endodontically treated cases.

\section{CLINICAL SIGNIFICANCE}

In the modern era of cosmetic dentistry that aims for esthetics and simultaneously at conservative approach for successful restorative outcome, use of walking bleach technique for whitening of discolored teeth can be considered as a relatively unchallenging, effective, and expedient method that can be used in clinical favor for patient as well as the clinician.

\section{REFERENCES}

1. Ingle, JI.; Beveridge, EE. Endodontics. 2nd edition. Philadelphia (PA): Lea and Febiger; 1976.

2. Cohen, SC.; Bums, RC. Pathways of the pulp. St. Louis (MO): C.V. Mosby; 1980.

3. MacIsaac AM, Hoen CM. Intracoronal bleaching: concerns and considerations. J Can Dent Assoc 1994 Jan;60(1):57-64.

4. Rostein, I. Tooth discoloration and bleaching. In: Ingle JI, Bakland LK, editors. Endodontics. 5th ed. Hamilton: BC Decker Inc.; 2002. pp. 845-860.

5. Ambalia SV, Ramgadhia HS. Nonvital tooth bleaching, noninvasive technique: a case report. IOSR J Dent Med Sci 2017 Mar;16(3):80-82

6. Nathoo SA. The chemistry and mechanism of extrinsic and intrinsic discoloration. J Am Dent Assoc 1997 Apr;128(Suppl):6S-10S.

7. Fasanaro TS. Bleaching teeth: history, chemicals and methods used for common tooth discolorations. J Esthet Dent 1992 May-Jun;4(3):71-78.

8. Goldstein RE. In-office bleaching: where we came from, where we are today. J Am Dent Assoc 1997 Apr;128(Suppl): 11S-15S.

9. Singh AK, Singh AK. Walking bleach: a case report. IJOCR 2013 Oct-Dec;1(2):55-58.

10. Rotstein I, Mor C, Friedmann S: Prognosis of intracoronal bleaching with sodium perborate preparations in vitro: 1-year study. J Endod 1993 Jan;19(1):10-12.

11. Spasser HF. A simple bleaching technique using sodium perborate. N Y State Dent J 1961 Aug;27(8-9):332-334.

12. Nutting EB, Poe GS. Chemical bleaching of discolored endodontically treated teeth. Dent Clin North Am 1967 Nov;11:655-622.

13. Zimmerli B, Jeger F, Lussi A Bleaching of non vital teeth. A clinically relevant literature review. Schweiz Monnatsschr Zahnmed 2010 Jan;120(4):306-320.

14. Yui KC, Rodrigues JR, Mancini MN, Balducci I, Gonçalves SE. Ex vivo evaluation of the effectiveness of bleaching agents on the shade alteration of blood-stained teeth. Int Endod J 2008 Jun;41(6):485-492.

15. Goldstein GR, Kiremidjian-Schumacher L. Bleaching: is it safe and effective? J Prosthet Dent 1993 Mar;69(3):325-328.

16. Almohareb T. Management of discoloured endodontically treated tooth using sodium perborate. J Int Oral Health 2017 Jun;9(3):133-135. 